\title{
Las Huelgas. Un Estudio Comparativo entre España y Argentina
}

Joaquim Juan Albalate ${ }^{1}$

Resumen: A pesar de que la huelga es el instrumento más universalmente utilizado por los trabajadores para defender sus intereses, el uso de ese instrumento en España ha tendido, en términos generales, a reducirse durante el período 2006-2016. Salvo en los años en que la crisis económico-financiera de 2008-2013 golpeó con más fuerza, la conflictividad laboral interpretada en términos de huelgas volvió a descender, esta vez, a cifras menores que las que había habido antes del inicio del citado período de crisis. En este trabajo analizamos la trayectoria que ha seguido el número de huelgas en España y Argentina durante el período 2006-2016. El análisis conjunto de las cifras de ambos países se realizó utilizando una serie de variables definidas a partir de las medias alcanzadas por los trabajadores que habían participado en esas huelgas, así como por las jornadas no trabajadas que también habían protagonizado esos mismos trabajadores en esas mismas huelgas. Los resultados del análisis muestran que, en todas las variables estudiadas, las cifras alcanzadas por los trabajadores argentinos que participaron en sus respectivas huelgas y, en particular, en la duración de las jornadas que no trabajaron fueron siempre mucho más elevadas que las que se

1 Profesor de la Universidad de Barcelona. jjuana@ub.edu

B CLIVATGE, número 6

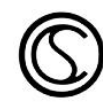


obtuvieron con las huelgas que protagonizaron los trabajadores españoles. El objetivo de la comparación es detectar aspectos relacionados con la variación en el uso de la huelga como instrumento de protesta.

Palabras clave: huelgas, participantes, jornadas no trabajadas, sindicatos

Resum: Malgrat que la vaga és l'instrument emprat de manera més universal pels treballadors per a la defensa dels seus interessos, el seu ús a Espanya ha tendit a disminuir, en termes generals, durant el període 2006-2016. Si n'exceptuem els anys en què la crisi econòmicfinancera de 2008-2013 va colpejar amb més força, la conflictivitat laboral interpretada en terme de vagues va tornar a descendir, aquesta vegada, a xifres menors que les que hi havia hagut abans del començament de l'esmentat període de crisi.

En aquest treball analitzem la trajectòria seguida pel nombre de vagues a Espanya i l'Argentina durant el període 2006-2016. L'anàlisi conjunta de las xifres de tots dos països es va dur a terme utilitzant una sèrie de variables definides a partir de les mitges de treballadors que havien pres part en les vagues, així com per les jornades no treballades protagonitzades per aquests mateixos treballadors en aquestes mateixes vagues. Els resultats de l'anàlisi mostren que, per a totes les variables estudiades, las xifres obtingudes pels treballadors argentins que van prendre part en les seves respectives vagues $i$, en particular, en la durada de les jornades que no van treballar van ser sempre molt més elevades que les xifres obtingudes per les vagues

B CLIVATGE, número 6

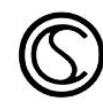


protagonitzades pels treballadors espanyols. L'objectiu de la comparació és detectar aspectes relacionats amb la variació en l'ús de la vaga com a instrument de protesta.

Paraules clau: vagues, participants, jornades no treballades, sindicats

Abstract: Although strikes are the most widely used instrument in the defence of labour interests, their use in Spain has shown a downward general trend in the period 2016-2016. If we exclude the years when the financial-economic crisis was at its highest point, labour conflictuality-measured as number of strikes-went down again to numbers even smaller than those before the beginning of the crisis. In this article, we analyse the trajectory followed by the number of strikes in Spain and Argentina in the period 2006-2016. The simultaneous analysis of the figures in both countries includes a set of variables which were defined based on the number of workers joining the strikes and the number of days that the participating workers were out of work. The results of our analysis show that, for all the variables included in it and, in particular, for the number of days out of work, the figures corresponding to the Argentinean workers were systematically much higher than those obtained by the Spanish workers. The goal of carrying out a comparative study of both countries was to identify elements of variation in the use of strikes as an instrument for protest.

Keywords: strikes, participants, days out of work, trade unions
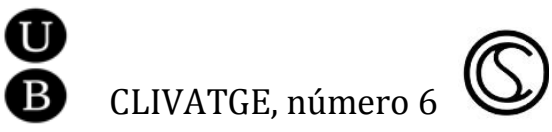
Este trabajo tiene por objeto conocer la evolución que han seguido las huelgas en España durante el período 2006-2016 para, posteriormente, compararlo con las que se han desarrollado en Argentina durante ese mismo período, a fin de deducir las causas que podrían explicar el distinto comportamiento de los trabajadores de ambos países a la hora de ejercer el derecho de huelga. La elección de Argentina no ha sido aleatoria, sino que se ha debido a que este país es el segundo del mundo en número de huelgas (OIT, 2012), por lo que constituye un buen referente con el cual contrastar lo que ha sucedido en España en materia de huelgas. Detectar esas causas permitirá saber cómo los trabajadores de distintos contextos económicos y sociolaborales reaccionan ante situaciones percibidas como injustas en el mundo del trabajo, de forma parecida o distinta en función del rol que juegan los sindicatos y el propio Estado.

La manifestación más singular del conflicto laboral, ya desde las primeras décadas del siglo XIX, ha sido la huelga que protagoniza la fuerza de trabajo. La huelga es el conflicto laboral más destacado y al que la literatura académica ha concedido mayor trascendencia, tanto por su relevancia social (las huelgas han involucrado a más trabajadores que cualquier otra forma de acción colectiva política $o$ social durante el siglo XX) como por su continuidad histórica (ya que desde mediados del siglo XIX las huelgas se convirtieron en la forma dominante de protesta social en las sociedades industriales capitalistas). No obstante, la huelga no fue reconocida legalmente en

B ClivatGe, número 6

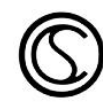


España hasta que se promulgó la Ley de Huelgas y Coligaciones en 1909 (Luque, 2013: 236, 238)

La literatura sobre las huelgas acaecidas desde primeros de los años noventa en España ha sido relativamente escasa en comparación con otras temáticas sociolaborales. No obstante, cabe destacar los trabajos realizados por (Alonso, 1991), (García Calavia, 2008), (Jiménez-Martínez et al, 1996), (Luque, 2013), (Marco y Tamborero, 2001), los cuales han analizado, desde diversas perspectivas, la temática de las huelgas. En ese sentido, algunas de estas aportaciones han hecho énfasis en la importancia que ha tenido para los trabajadores la consagración constitucional del derecho de huelga en España pues, de no haber sido constitucional ese derecho, la degradación de las condiciones a las que hoy se ha llegado, aún habrían sido mucho peores.

La huelga es una acción colectiva de cese temporal del trabajo por parte de un conjunto de trabajadores, para expresar una queja u obtener unas determinadas decisiones o modificaciones de actitudes de quienes emplean a tales trabajadores (Hyman, 1984). Es una acción temporal, porque se entiende que unos trabajadores que luchan por unas determinadas mejoras lo hacen porque tienen la intención de seguir trabando en la empresa con la que mantienen el conflicto, sólo que con esas mejoras. De no obtener esas mejoras podría desencadenarse un conflicto laboral en términos de paro de la actividad con consecuencias no siempre previsibles para ambas partes. Si la huelga estuviera planificada por la mayoría de los trabajadores para lograr su despido, y no una serie de reivindicaciones en esa empresa, el término huelga dejaría de tener

B CLIVATGE, número 6

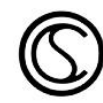


sentido. Otra cosa muy distinta sería que, finalmente, el resultado último no previsto de la huelga fuera el despido. Y es una acción laboral, porque va dirigida contra los empresarios que contratan a los que ejercen la huelga pero no contra el Estado -a no ser que éste sea el empleador - o contra otros trabajadores de otras empresas o sectores de actividad.

En general, la huelga no sólo puede obedecer a una presión a la patronal para el logro de mayores salarios o de mejores condiciones de trabajo, sino que también puede responder a diversas motivaciones: protesta por algún problema específico de una empresa o sector; por reclamación de algo externo a lo pactado en el convenio; por solidaridad con otros trabajadores en huelga; etc. Pero también para presionar políticamente contra determinadas decisiones gubernamentales (huelga general), por considerarlas clara $\mathrm{y}$ únicamente favorables a los empresarios (Duarte, 2007).

Paradójicamente, las huelgas "generales" en España se dirigen casi siempre contra el Estado -controlado por el gobierno de turno que, a su vez, representa los intereses de los partidos políticos que ganaron las últimas elecciones políticas (de ámbito estatal, en este caso), y que, a su vez, representan los intereses económicos y sociales de los que los votaron- pero casi nunca, contra la patronal -al menos como único objetivo- a pesar de que es la que, objetivamente, más motivos podría haber creado para que los trabajadores decidieran movilizarse en su contra pues, las políticas gubernamentales que son percibidas por los sindicatos y trabajadores como lesionadoras de sus derechos y condiciones de trabajo suelen ser, antes que nada, el resultado de la presión exitosa ejercida, previamente, por la patronal.

B CLIVATGE, número 6

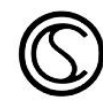


Históricamente, han sido los trabajadores quienes más han defendido la presencia del Estado en el mercado de trabajo, en la economía y en la propia sociedad -como medio para contrarrestar el poder preponderante de la clase empresarial capitalistas- por lo que han confiado en su respaldo para regular e intentar neutralizar las injustas, y a menudo, degradantes condiciones con las que los empresarios han contratado el trabajo de los primeros.

De otro lado, y ya en el contexto democrático actual de España, la gran mayoría de las huelgas se realizan con carácter legal, es decir, bajo ciertas normas básicas, previamente pactadas y reguladas por los agentes sociales. Cuando eso no sucede, se suele hablar de "huelga salvaje" o "ilegal". Ahora bien, que una huelga pueda ser calificada de "salvaje" por la autoridad púbica - porque, supuestamente, se salta las normas establecidas o porque pueda producir perjuicios de difícil reparación (colapsos circulatorios urbanos, servicios mínimos no respetados en los servicios públicos, etc.) - podría estar impidiendo la realización de esa huelga por motivos de carácter "político" que se apartan del objetivo de esa ley y, por tanto, del control social formal que esta ejerce, en este casi, en el ámbito del conflicto laboral- más allá de los perjuicios que se pudieran derivar para la sociedad.

\section{LOS MOTIVOS DE LAS HUELGAS. UN BALANCE DE LA TEORÍA}

Hay dos grandes enfoques que nos orientan en la explicación sobre las causas del aumento o declive de las huelgas: el económico-racionalista y el institucionalista-organizativo. El primero, concibe la huelga como una decisión "racional" que toman los trabajadores en función de la situación en que se encuentra la economía. Así, si la posición de

B ClivatGe, número 6

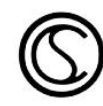


los trabajadores en el mercado de trabajo es robusta y el ciclo económico es expansivo, la fuerza de negociación que adquieren los trabajadores tenderá a ser elevada y, por tanto, una huelga podría conseguir sus objetivos (Ashenfelter \& Johnson, 1969). Al contrario, la propensión a la huelga de los trabajadores declinaría durante las fases en que el ciclo económico tienda a la contracción, con lo que su posición negociadora se deteriorará, por lo que será más fácil que sean despedidos. Es decir, cuando el mercado de trabajo está más o menos ajustado o equilibrado, es más viable que los trabajadores asuman menos riesgos por ir a la huelga porque, en caso de despido, es más fácil de compensarlo al haber más oportunidades de empleo. Además, en el supuesto de pleno empleo, el empresario tiene más dificultades para sustituir a los huelguistas en el mercado de trabajo, a lo que habría que sumar que una interrupción del proceso productivo puede suponerle una importante caída de las ventas y, por tanto, de los beneficios.

En cuanto a la perspectiva institucionalista-organizativa, autores como (Tilly y Shorton, 1971), (Korpi, 1978), (Goldthorpe, J, 1991) o (Korpi y Shalev, 1979), entre otros, defienden que la lucha por la redistribución de la renta que se inició tras la Segunda Guerra Mundial se canalizó, básicamente, a través de los gobiernos socialdemócratas. El recurso al Estado permitió a los trabajadores contrarrestar la inercia, normalmente negativa, que resultaba de dejar, exclusivamente en manos del mercado, esa redistribución ${ }^{2}$.

${ }^{2}$ Así, eso facilitó que buena parte de las reivindicaciones que el movimiento obrero europeo había planteado en términos de intensas y constantes huelgas, ya desde los años treinta, disminuyera sustancialmente. La socialdemocracia se

B CLIVATGE, número 6

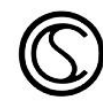


A partir de finales de la década de los setenta y primeros de los ochenta, el recurso de los trabajadores al amparo del Estado decayó notablemente. La generalización de las políticas neoliberales en casi todos los países europeos conduciría a una situación en la que las relaciones laborales volverían a situarse en la dualidad patronalsindicatos propia de antes de la Segunda Guerra Mundial. El Estado volvería a ejercer el papel de ausente para que sólo esos dos agentes sociales protagonizaran la confrontación o negociación colectiva de sus respectivos intereses, dando lugar a una nueva etapa en la que la hegemonía en las relaciones laborales no ha dejado de decantarse en favor de la patronal y donde la posición de los sindicatos europeos se ha vuelto a debilitar tanto o más que antes de la Segunda Guerra Mundial.

Por lo que hace a España, el crecimiento espectacular del número de huelgas que se desarrollaron durante los primeros años de la transición política (al final del período 1976-1979 se alcanzaron cifras de jornadas no trabajadas que llegaron a situarse alrededor de los diecinueve millones), se vio, rápidamente, atenuado ${ }^{3}$ para ubicarse, a partir de 1980, en una senda mucho menos conflictiva. Sin embargo, eso no obvia para que se hayan seguido registrando

encargó, a cambio de pactos sociales con los sindicatos, de asumir muchas de esas reivindicaciones, aplicando un aumento sistemático de los salarios reales y de otro tipo de beneficios en el empleo, así como de una política fiscal favorable a los trabajadores.

3 Ver la explicación de esta etapa en Luque, D. et al (2008), Un análisis regional de la actividad huelguística en España, Revista Española de Investigaciones Sociológicas, 124, pp. 107-140.
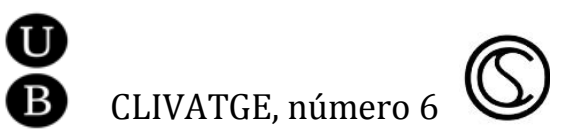
numerosas huelgas que han desafiado al mercado como único distribuidor de las rentas, ni que se haya dejado de apelar al Estado para obtener de él algo que, sin él, difícilmente obtendrían los trabajadores, por mucho que ese Estado esté sometido al control político de la patronal y del neoliberalismo económico.

Tampoco en tal senda se ha obviado que, aunque con fluctuaciones constantes, tanto por motivos económicos, como por causas de orden político-organizativo, se haya producido un número importante de huelgas, tanto generales como sectoriales y locales, tanto en el sector público como en el privado. Los datos de esa senda indican que el comportamiento numérico actual del volumen de conflictos puede compararse con el que han seguido países como Alemania o Italia.

Desde el punto de vista organizativo, hace unos años que apareció la denominada teoría de la confianza. Según uno de sus autores más reconocidos, Simon Joyce, la confianza de los trabajadores podría constituir una de las causas que podría explicar el continuado bajo nivel de luchas y huelgas que se han desarrollado durante los últimos treinta años (Joyce, 2015: 5). Según este autor, las consecutivas derrotas que han sufrido los trabajadores durante las últimas décadas podrían haber socavado su confianza en su capacidad para derrotar a los empresarios y a la patronal para conseguir sus reivindicaciones mediante el ejercicio de la huelga.

A la creación de esa desconfianza, habría contribuido, enormemente, el denominado "efecto demostración", o lo que es lo mismo, que, habiéndose perdido numerosas huelgas en el pasado, la

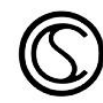


probabilidad de que un trabajador quiera volver a correr el riesgo de vivir esa misma experiencia sería cada vez menor (Joyce, 2015: 10).

No obstante, este mismo autor reconoce que, desde una perspectiva histórica, la confianza ha sido sólo una variable más a tener en cuenta para explicar el descenso que ha habido de las huelgas. Es decir, no ha determinado, por si sola, toda la causalidad del declive del recurso a la huelga que se viene viviendo en Europa desde finales de los años setenta. Por ejemplo, muchas de las huelgas que se han declarado, no han surgido de la confianza que tenían los trabajadores, sino de su desesperación ante unas determinadas condiciones de trabajo. También otras huelgas se han realizado, sin que, aparentemente, apareciera la confianza como determinante de esas huelgas.

Se admite pues, que la teoría de la confianza posee una debilidad subyacente al no abordar cómo esa confianza puede convertirse en huelgas: si el nivel de huelgas refleja el nivel de confianza de los trabajadores, tendría que haber algún tipo de conexión entre ambas variables, de modo que una creciente confianza se tendría que traducir en un aumento del nivel de huelgas. Y eso no sólo es una gran simplificación de un proceso complejo (Joyce, 2015: 4), sino que no siempre se ha podido demostrar.

Sin embargo, bien es cierto que durante la década de los sesenta el pleno empleo consiguió la "confianza" de los trabajadores en su confrontación con los empleadores. "Si te despedían era fácil encontrar otro empleo". Y es que, los beneficios de los capitalistas eran entonces considerados suficientes para hacer concesiones a los trabajadores. No obstante, a partir de mediados de los 80's se

B ClivatGe, número 6

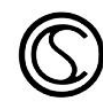


produjeron una serie de sucesos que modificaron, radicalmente, ese contexto. En primer lugar, se implementó la reestructuración sectorial, que afectó profundamente a las industrias más sindicadas y que más huelgas planteaban. En segundo lugar, se llevaron a cabo cambios importantes en las normativas laborales que restringieron los supuestos legales que amparaban el ejercicio de las huelgas (Joyce, 2015: 12) y, finalmente, y en particular, se desarrolló la burocracia sindical en casi todos los países europeos (Joyce, 2015: 4, citando a Callinicos). Con todo ello, se consiguió reducir, sustancialmente, el número de huelgas.

En este último sentido, la disminución de los conflictos se ha atribuido, de manera particular, al papel que ejercían los delegados sindicales más antiguos y liberados a tiempo completo, al distanciarse de la experiencia cotidiana, lo cual condujo a que desarrollaran una perspectiva sindical cada vez más conservadora, de cuyo resultado se derivó un freno de las luchas obreras. Es lo que Cliff denominó "efecto reflujo" (Joyce, 2015: 6), citando a Cliff. Con posterioridad, ese control dejaría de estar en manos de los delegados sindicales para acabar siendo de usufructo exclusivo de los principales dirigentes sindicales, dando lugar a lo que se ha denominado como "burocracia sindical". Desde hace unos años, se ha hecho muy difícil ir a la huelga de manera independiente sin el control de los grandes sindicatos. Según Joyce, este sería el principal obstáculo a superar para que puedan aumentar las huelgas como expresión del resurgimiento de la confianza de los trabajadores (Joyce, 2015: 5).

Todo lo anterior, ha implicado: a) la inmensa mayoría de las huelgas actuales son oficiales, b) son cortas y discontinuas, c) cada vez

B CLIVATGE, número 6

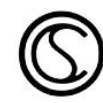


son más locales y sectoriales que nacionales, y d) dada la obligación de una consulta directa previa a los trabajadores, eso complica y alarga la negociación colectiva. Todo conduce a que los conflictos se intenten resolver por la vía de la negociación y que la huelga sea sólo el último recurso.

Además de los factores apuntados por los enfoques económico e institucional en los párrafos anteriores, no debería descartarse el impacto que ha tenido el neoliberalismo en el empleo de los trabajadores y, por consiguiente, en un potencial descenso de las huelgas. En primer lugar, como consecuencia de la descentralización y deslocalización de la producción y del trabajo y de la automatización de los procesos de trabajo, se ha deparado una disminución del tamaño medio de las empresas, con lo que, se ha minado la resistencia de los trabajadores para hacer huelga (Joyce, 2015: 3), citando a Davidson. En segundo lugar, como consecuencia de la transmisión a los trabajadores de la ideología neoliberal en el mundo del trabajo (incremento de los valores instrumentales, de la eficiencia productiva, del consumismo, etc., por ejemplo), se consiguió, junto a otros factores, socavar el colectivismo en la clase obrera (Joyce, 2015:4), citando a Brown.

En realidad, hay una serie de procesos importantes que median entre el sentimiento de agravio que puede percibir uno o más trabajadores para que ese sentimiento se traduzca, efectivamente, en una protesta laboral. Así, según Kelly, el proceso de concienciaciónacción para que se forme la predisposición a hacer huelga seguiría la siguiente trayectoria encadenada: en el contexto del lugar de trabajo, la insatisfacción que puede padecer un trabajador ha de ser vivida por

B CLIVATGE, número 6

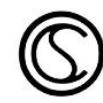


éste como una "injusticia"; la injusticia debe ser vista como una cuestión "colectiva" y la causa de la injusticia colectiva ha de imputarse, nítidamente, al empleador. A partir de aquí, los trabajadores han de calcular las posibilidades de éxito de la posible protesta laboral, a fin de evaluar si los beneficios son mayores que los costes, atendiendo al grado de capacidad organizativa que se dispone en la organización en cuestión para que la acción de protesta se lleve a la práctica con éxito.

En todo este proceso, el papel de los líderes en el lugar de trabajo es, a menudo, crucial. Si hay problemas en cualquiera de esas "etapas", incluyendo la falta de liderazgo, el resultado probable es que el sentimiento de agravio subyacente (el de injusticia), no dé lugar a una acción colectiva (Joyce, 2015: 4), tanto si se plantea en términos de conflicto laboral (sin pretender explícitamente una huelga), como si se deriva, efectivamente de él, una huelga.

En definitiva, que existan ideas colectivistas o protestas colectivas eso no significa que, necesariamente, exista la confianza de los trabajadores para hacer huelga (Kelly, 1998). Tampoco que un bajo nivel de huelgas sea una prueba directa de falta de combatividad de los trabajadores o sea una a expresión de un bajo nivel de confianza. Los delegados sindicales, los afiliados y una parte importante del resto de trabajadores, no sólo siguen teniendo motivos para hacer huelga, sino que, si no la hacen, no es porque hayan perdido la conciencia de lo que es justo y lo que no (Joyce, 13).

Además, muchas de las acciones de protesta y de las pequeñas luchas o huelgas que suceden dentro de los centros de trabajo no tienen visibilidad porque no llegan a los registros oficiales de huelgas

B CLIVATGE, número 6

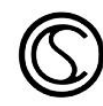


a pesar de haberse producido. De hecho, las quejas y las reivindicaciones siguen existiendo en todos los centros de trabajo $y$, es más que probable que seguirán existiendo mientras las relaciones de y en la producción generen desigualdades.

\section{LOS DATOS EMPÍRICOS SOBRE LAS HUELGAS EN ESPAÑA}

Sobre las huelgas existe en España un amplio registro administrativo que se publica anualmente desde 1986. La información de esta investigación parte de los datos que recoge la principal fuente estadística a nivel estatal y por Comunidades Autónomas: la Estadística de Huelgas y Cierres Patronales que confecciona el actual Ministerio de Empleo y Seguridad Social y que proporciona información sobre una serie de variables relacionadas con las huelgas.

En ese sentido, aquellos individuos o sindicatos que promueven una huelga tienen la obligación legal de comunicarlo a la autoridad laboral correspondiente. Tras la autorización de una huelga, la Subdirección General de Estadística de ese Ministerio realiza un seguimiento mensual de una serie de características de las huelgas hasta que finaliza el conflicto. En esta fuente no se contemplan las consecuencias indirectas sobre terceras empresas que pueden padecer como consecuencia de tales huelgas, por ejemplo, paros involuntarios en el proceso productivo como resultado de, por ejemplo, ausencia o escasez de provisión de materias primas por efectos de las huelgas de los primeros.

Hay, de entrada, tres variables básicas que miden el impacto de las huelgas: el número de huelgas, el número de participantes y el número de jornadas no trabajadas. Mientras el número de huelgas

B ClivatGe, número 6

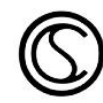


tiende a relacionarse con las condiciones económicas que han dado lugar a la convocatoria de esas huelgas pero no da información del alcance del volumen de trabajadores implicados, en cambio, la segunda, es un buen indicador del número de participantes que se han involucrado en las huelgas habidas a lo largo de cada año. Finalmente, la tercera variable refleja la intensidad del "daño" directo infligido a las empresas y organizaciones en términos del total de jornadas no trabajadas sin contar con el "daño" indirecto producido como consecuencia de las repercusiones habidas en terceras personas o empresas que no hayan participado en tales huelgas pero hayan sufrido también algunos de sus efectos ${ }^{4}$.

Pues bien, en esta investigación se ha procedido a realizar, en una primera etapa, un análisis descriptivo de la evolución de las huelgas que se han desarrollado en España durante el período 1998-2016, para pasar a observar, posteriormente, la relación entre los porcentaje de centros y plantillas convocados y los porcentajes de los centros y plantillas implicados para, finalmente, analizar la evolución que han seguido las nuevas variables que figuran en el Cuadro 2, en términos de medias de participantes y de jornadas de trabajo en función del número de huelgas que hubieron durante ese período.

En una segunda etapa, se ha procedido a realizar un análisis descriptivo comparativo de las huelgas habidas en Argentina y España

\footnotetext{
${ }^{4}$ Este registro también hace referencia a la información sobre los centros y los correspondientes trabajadores convocados a las huelgas, así como a la respuesta real habida de esos mismos centros y trabajadores a dichas convocatorias.
}

B CLIVATGE, número 6

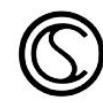


durante el mismo período 2006-2016, con el objetivo de ver la evolución seguida, en este caso, por las medias de participantes y de jornadas no trabajadas en función del número de huelgas y de los ocupados 5 de ambos países, para comprobar si los resultados obtenidos del análisis de estas dos variables realizado, de forma independiente en la primera etapa, se correspondían con los obtenidos con las nuevas variables (Medias de participantes por huelga y Medias de jornadas no trabajadas por huelga), a todo lo cual se añadió dos nuevas variables ("Medias de ocupados por participante" y "Medias de ocupados por jornadas no trabajadas") para intentar deducir nuevos resultados fruto de su comparación.

\section{ANÁLISIS DE LAS HUELGAS EN ESPAÑA}

\section{1 Las huelgas en España 1998-2016}

Dicho lo anterior, se exponen a continuación las cifras de huelga que se han desarrollado en España durante el período 1998-2016:

\section{Evolución de las huelgas desarrolladas en España, 1998-2016. Cuadro 1}

\begin{tabular}{|c|c|c|c|c|c|c|c|}
\hline \multirow[t]{2}{*}{ Año } & \multirow[t]{2}{*}{ Huelgas } & \multirow[t]{2}{*}{ Participantes } & \multirow{2}{*}{$\begin{array}{r}\text { Jornadas no } \\
\text { trabajadas }\end{array}$} & \multicolumn{3}{|c|}{ Centros de trabajo convocados } & \multirow{2}{*}{$\begin{array}{c}\begin{array}{c}\text { Centros de } \\
\text { trabajo } \\
\text { implicados }\end{array} \\
\text { Plantilla }\end{array}$} \\
\hline & & & & Número & Plantilla & Número & \\
\hline 1998 & 618 & 671.878 & 1.263 .536 & 118.642 & 1.906 .995 & 56.695 & 1.493 .668 \\
\hline 2000 & 727 & 2.061 .349 & 3.577 .301 & 722.129 & 6.096 .555 & 578.672 & 5.380 .646 \\
\hline 2002 & 684 & 4.528 .210 & 4.938 .535 & 2.063 .113 & 17.390 .775 & 1.603 .767 & 15.361 .933 \\
\hline
\end{tabular}

${ }^{5}$ Las cifras de la población ocupada de Argentina de 2015 no se han podido obtener debido a los problemas de contabilización de estas cifras por parte del Ministerio de empleo, trabajo y seguridad social de Argentina. 


\begin{tabular}{|c|c|c|c|c|c|c|c|}
\hline 2004 & 707 & 555.832 & 4.472 .191 & 74.615 & 1.607 .051 & 67.435 & 1.346 .916 \\
\hline 2006 & 779 & 499.240 & 927.402 & 130.298 & 1.504 .155 & 108.232 & 1.201 .288 \\
\hline 2007 & 751 & 492.150 & 1.182 .782 & 45.235 & 1.429 .204 & 41.625 & 1.279 .684 \\
\hline 2008 & 810 & 542.508 & 1.508 .719 & 581.350 & 5.860 .468 & 74.128 & 1.229 .000 \\
\hline 2009 & 1001 & 653.483 & 1.290 .852 & 105.830 & 1.502 .572 & 73.026 & 1.150 .149 \\
\hline 2010 & 984 & 340.776 & 671.493 & 46.393 & 1.332 .668 & 32.840 & 1.140 .118 \\
\hline 2011 & 777 & 221.974 & 485.054 & 304.341 & 3.344 .081 & 49.062 & 980.477 \\
\hline 2012 & 878 & 323.871 & 1.290 .114 & 36.636 & 1.363 .080 & 33.875 & 1.326 .110 \\
\hline 2013 & 994 & 448.024 & 1.098 .480 & 45.832 & 1.633 .924 & 42.327 & 1.512 .676 \\
\hline 2014 & 777 & 217.047 & 620.568 & 7.666 & 618.478 & 7.575 & 614.792 \\
\hline 2015 & 615 & 170.528 & 497.486 & 4.939 & 588.359 & 4.153 & 539.818 \\
\hline 2016 & 641 & 183.120 & 388.912 & 10.473 & 583.524 & 9.679 & 563.451 \\
\hline
\end{tabular}

Fuente: Estadísticas de huelgas y cierres patronales, Ministerio de Empleo y Seguridad Social

La observación del Cuadro 1 permite apreciar que, a lo largo del período 1998-2016, se registró un cierto vaivén en el crecimiento y decrecimiento del número de huelgas que hubo en España a lo largo de ese período. De ese modo y, en términos absolutos, el número de huelgas que, por ejemplo, se registró en 1998 (618), resultó ser muy parecido al que acabó registrándose en 2015 (615) o, incluso, en 2016 (641), a pesar de que fuera, probablemente, por motivos un tanto diferentes. Mientras en 1998 pudo deberse a una baja conflictividad por la existencia de una economía en expansión donde el crecimiento del empleo y la mejora de las condiciones de trabajo se encargaban de ocultar la existencia de otros problemas no resueltos en 2016 (contratos temporales, economía sumergida, accidentes de trabajo, paro de los más jóvenes, etc.), en cambio, esas parecidas cifras de conflictividad podrían atribuirse a la existencia de un contexto con un discreto crecimiento económico, a expensas de la salida, aún 
hipotética, de una crisis económico-financiera altamente devastadora para el empleo, donde el crecimiento del número de huelgas fue, relativamente, escaso en el sector público y, prácticamente, negativo en el privado.

Durante la primera etapa hasta los inicios de la crisis (19982008), la movilización de los trabajadores fue, relativamente, intensa. En ese sentido, el progresivo incremento de la conflictividad laboral que arrancó ya desde 1995, acabó culminando en 2002 con la convocatoria de una huelga general por parte de los principales sindicatos, por motivos, claramente políticos, en contra de las políticas neoliberales regresivas para los trabajadores practicadas por el Gobierno de mayoría absoluta del Partido Popular (20002004), más nefastas aún, si cabe, que las que ya se habían implementado durante el primer mandato de este partido sin disponer de la citada mayoría.

Tras el retorno del PSOE al Gobierno central en 2004, no por ello las cifras de conflictividad laboral declinaron pues el número de huelgas y de participantes y de jornadas no trabajadas en las huelgas siguió creciendo hasta 2009. A partir de 2010, la tendencia -en cuanto a estas dos variables se refiere- fue declinando lentamente, aunque con oscilaciones, pero con cifras en ambas variables, tendencialmente a la baja -salvo en 2012, por la convocatoria de una huelga general ante la séptima reforma laboral desde el inicio de la democracia- en especial, a lo largo de los años, 2014 y 2015. No obstante, las cifras alcanzadas en 2016 supusieron un pequeño repunte (26 huelgas más que en 2015), aunque eso apenas alteró los niveles que se registraron en los dos años inmediatamente anteriores,

B CLIVATGE, número 6

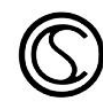


de modo que el volumen de huelgas de 2016 supuso la tercera cifra más baja en los últimos veinte años, sólo por encima de las registradas en 1998 y 2015. En los conflictos de 2016 participaron 183.120 trabajadores, una cifra algo superior a la de 2015 (7,4 por 100 de más).

El incremento en el número de participantes no fue óbice, sin embargo, para que se diese un nuevo y acusado descenso en el volumen de jornadas no trabajadas, arrojando cifras (388.912) de un $21,8 \%$ menos que en 2015 , la cifra más baja de los últimos diez años, lo que parece apuntar a una menor duración media de los conflictos.

Por lo que se refiere al impacto que tuvieron las convocatorias de huelgas en los centros de trabajo y en la respuesta de las plantillas de estos centros a esas convocatorias, es fácil comprobar que, salvo en la convocatoria de huelga efectuada en 2011 o en las respuestas ofrecidas por los trabajadores a las convocatorias de 2012 y 2013, las cifras absolutas alcanzadas por esas variables no superaron nunca las que se produjeron durante la etapa anterior.

En su conjunto, las huelgas en España vienen mostrando en los últimos años un panorama de dimensión media relativamente reducida más, si se tiene en cuenta que la fuente "Estadística de huelgas y cierres patronales", de donde proceden estos datos, no recoge, entre otros, las huelgas generales de ámbito nacional (CES, 2017, 439).

Por otro lado, aunque las tendencias enumeradas anteriormente parecen ser bastante evidentes, es necesario matizar las afirmaciones realizadas hasta estos momentos. Y es que, desde que se aprobara por parte de las organizaciones sindicales y patronales más

B CLIVATGE, número 6

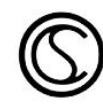


representativas (CCOO, UGT, CEOE Y CEPYME), el denominado "Acuerdo sobre Solución Extrajudicial de Conflictos" (ASEC) y de la misma puesta en marcha -descentralizada en algunas Comunidades Autónomas- del "Servicio Interconfederal de Mediación y Arbitraje" (SIMA) desde 1996; el número de conflictos colectivos y, por tanto, de trabajadores y empresas que, desde 1998, vienen sometiéndose a un intento voluntario (adhiriéndose al ASEC), para resolver extrajudicialmente sus diferencias, ha influido, significativamente, a la baja en las cifras de la conflictividad laboral y, por tanto, en el número de huelgas que, efectivamente, se producen.

Así, por ejemplo, entre 2001 y 2010 el número de conflictos que se tramitaron para su mediación y arbitraje ante los órganos autonómicos de solución extrajudicial fue de 39.804, con una media de 3.980 conflictos por año, aunque en constante crecimiento, año a año. Ese crecimiento se debió al aumento de la conflictividad en España, en particular, como ya se ha comentado, a partir de 2008, con la aparición de la crisis económico-financiera ya citada, pero también al relativo éxito que ha tenido esta iniciativa, tanto entre los empresarios, como entre los trabajadores (a veces, utilizado por éstos a nivel individual), y sus propios representantes. Es posible pensar, por tanto, que de no haber existido ambos órganos (el SIMA y el ASEC), la probabilidad de haber aparecido más conflictos y huelgas que los que, realmente, se registraron, habría sido mucho más elevada.

\subsection{Las huelgas en España desde una perspectiva relativa}

B CLIVATGE, número 6

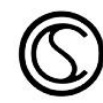


Más allá de la aparente tendencia al declive de la conflictividad laboral expresada en las variables comentadas en el epígrafe anterior, parecería desprenderse de todo ello, tal como ya se apuntaba en el epígrafe 3 anterior, la existencia de dos etapas distintas en el grado de conflictividad (una primera en ascenso, hasta 2009, otra posterior, en descenso, a partir de 2010). Pues bien, sería interesante comprobar si los datos obtenidos en la segunda etapa, con tendencia al descenso de la conflictividad, alcanzarían la misma trayectoria si se trataran esas variables en términos relativos.

Para ello, se expone a continuación el Cuadro 2 en el que se muestran las nuevas variables, procedentes del cruce de las utilizadas en el Cuadro 1 y para el período 2008-2016. La elección de este período responde a la voluntad de poder ver -aunque sólo sea en términos descriptivos- en qué medida, los resultados obtenidos con esas nuevas variables coinciden o no con la tendencia a la baja conflictividad detectada con el análisis efectuado en términos absolutos.

Evolución de las medias por huelgas, participantes y jornadas de trabajo desarrolladas en España, 2009-2016. Cuadro 2 


\begin{tabular}{|c|c|c|c|c|}
\hline Año & $\begin{array}{c}\text { Media de } \\
\text { participantes por } \\
\text { huelga }\end{array}$ & $\begin{array}{c}\text { Media de jornadas } \\
\text { no trabajadas por } \\
\text { huelga }\end{array}$ & $\begin{array}{c}\text { \% centros } \\
\text { implicados sobre } \\
\text { centros convocado }\end{array}$ & $\begin{array}{c}\% \text { plantilla } \\
\text { implicada sobre } \\
\text { plantilla } \\
\text { Convocada }\end{array}$ \\
\hline 2009 & 652,8 & $1.289,5$ & $69,-\%$ & $76,5 \%$ \\
\hline 2010 & 288,7 & 682,4 & $70,7 \%$ & $85,5 \%$ \\
\hline 2011 & 285,6 & 624,2 & $16,1 \%$ & $29,3 \%$ \\
\hline 2012 & 368,8 & 1469,3 & $92,4 \%$ & $97,3 \%$ \\
\hline 2013 & 450,7 & $1105,-$ & $92,3 \%$ & $92,6 \%$ \\
\hline 2014 & 279,3 & 798,6 & $98,8 \%$ & $99,4 \%$ \\
\hline 2015 & 277,3 & 808,9 & $84,-\%$ & $91,7 \%$ \\
\hline 2016 & 285,7 & 606,7 & $92,3 \%$ & $96,5 \%$ \\
\hline
\end{tabular}

Fuente: Elaboración propia, a partir de Estadísticas de huelgas y cierres patronales, Ministerio de Empleo y Seguridad Social

Si bien tampoco es posible detectar algún comportamiento regular de los resultados obtenidos con las nuevas variables examinadas en el Cuadro 2 anterior, sí se pueden deducir algunas consecuencias que aportan matizaciones a los resultados descritos en el Cuadro 1 anterior.

Para empezar, se puede corroborar con estas nuevas variables, la tendencia a la baja -salvo en 2012 y 2013- del promedio de trabajadores que participaron en las huelgas desde 2009 hasta 2016, con un descenso acusado en 2014 y 2015, aunque con un nuevo pero leve remonte en 2016. En segundo lugar, se constata también un descenso remarcable de las jornadas perdidas por huelga, salvo en 2012, para llegar al 2016 con una cifra de 606,7 jornadas perdidas de media, que pone esta variable en el nivel más bajo del citado período. 
En otras palabras, mientras parecería haberse producido una pequeña recuperación de la media relativa de la participación de los trabajadores en las huelgas en $2016(285,7)$-volviendo a situarse en los niveles de 2010 y 2011-; en cambio, la media relativa de las jornadas no trabajadas por huelga, a pesar de que ha seguido un itinerario desigual desde que en 2012 alcanzara su nivel máximo, ha ido, en promedio, a la baja, cosechando el mayor descenso relativo de dichas variables en 2016.

Finalmente, el análisis comparativo entre el porcentaje de centros implicados en las huelgas y los centros convocados y ese mismo cálculo para las respectivas plantillas, ha deparado unos resultados un tanto sorprendentes, en cuanto a la eficacia que han tenido tales convocatorias, sobre todo, durante los últimos cinco años estudiados. Así, el porcentaje con el que los sindicatos fueron capaces de implicar a los trabajadores en las diversas convocatorias de huelgas a lo largo del período 2009-2016, ha sido casi siempre creciente y, sobre todo, claramente elevado, salvo en 2011, tanto en lo que se refiere al número de centros convocados e implicados, como en lo que respecta a los trabajadores implicados de esos centros en esas convocatorias.

La eficacia del seguimiento de los trabajadores conseguido por los sindicatos convocantes llegó a alcanzar porcentajes superiores al 90\% entre 2012 y 2016, justo cuando el número de centros convocados adquiría las cifras más bajas de todo el período analizado, a pesar de que en 2015 esa trayectoria inició un pequeño retroceso, aunque fue restaurado en 2016.
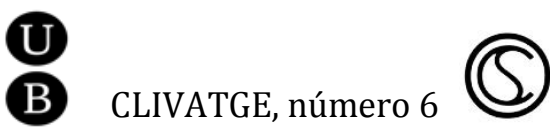
En consecuencia, vistos los anteriores resultados, se podría abrir la hipótesis de que la eficacia de los sindicatos españoles en cuanto a conseguir un seguimiento elevado de los trabajadores en las huelgas por parte de éstos ¿es mayor cuando el número de centros convocados es menor y, por tanto, es más fácil para los sindicatos controlar el seguimiento sectorial o territorial de las huelgas?

Por otro lado, sería fácil también abrir otra hipótesis en el sentido de que, si hubo un seguimiento tan elevado -salvo en 2011tanto de los centros como de las plantillas convocadas desde 2009, ¿por qué los sindicatos no aprovecharon esa coyuntura para convocar nuevas huelgas, habiendo motivos de sobras para hacerlo, si se tiene en cuenta el panorama de recortes salariales y sociales y de precariedad laboral que existía (y existe) desde entonces, o ¿es que tales sindicatos dedujeron, quizás erróneamente, que no habría suficiente respuesta de los potenciales trabajadores a convocar?, o ¿fue porque, por el contrario, se sumaron a la decisión política del gobierno y la patronal de esos momentos para no incrementar el número de conflictos ante una situación difícil de la economía, a pesar de que existía un clima propicio, como se ha visto, a responder mayoritariamente a tales convocatorias, aunque fuera sólo allí donde se plantearon?

En resumen, la trayectoria que ha seguido, tanto en términos absolutos como relativos, el número de huelgas, de participantes o de jornadas no trabajadas, no permite asegurar que la existencia de huelgas haya ido claramente a la baja pero tampoco al alza. Sólo se puede aseverar que el grado de implicación que han conseguido los

B CLIVATGE, número 6

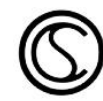


sindicatos de los trabajadores en los centros de trabajo en los que se han convocado huelgas desde 2012 hasta 2016, la eficacia de esa implicación ha sido muy elevada (por encima del 84\%), mientras que esa eficacia ha superado el $90 \%$ en el caso de las plantillas convocadas.

\section{ANÁLISIS COMPARATIVO DE LAS HUELGAS HABIDAS EN ARGENTINA Y ESPAÑA 2006-2016}

\subsection{Análisis de las variables en términos absolutos}

A continuación, se procederá a hacer un análisis comparativo de las huelgas que se han desarrollado en España y Argentina durante el período 2006-2016. Este análisis, de carácter descriptivo, se centrará en la observación de la evolución habida en las huelgas, los participantes y las jornadas no trabajadas de ambos países, para deducir e interpretar las semejanzas y diferencias que se han producido en las series anuales de los citados datos. Se excluye, por tanto, el análisis comparativo de los centros de trabajo y de las respectivas plantillas convocados $\mathrm{y}$, por tanto, del grado de implicación de tales centros y plantillas en dichas huelgas.

Tal como se muestra en el Cuadro 3 que viene a continuación, desde 2006 hasta 2011, el número de huelgas que se desarrollaron en ambos países se mantuvo, relativamente, estable, con algunos altibajos por parte de los dos países. Sin embargo, a partir de 2011 y hasta 2016, se inició un incremento de este tipo de conflictos, en particular, en Argentina, mientras que se registraba una tendencia

B CLIVATGE, número 6

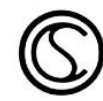


general a la disminución en España, a pesar de que, en 2015, se puede apreciar que también en Argentina se originó un repunte a la baja.

Evolución de las huelgas, participantes y jornadas no trabajadas en España y Argentina, 2006-2016. Cuadro 3

ESPAÑA

\begin{tabular}{|c|c|c|c|c|c|c|}
\hline Año & Huelgas & Participantes & $\begin{array}{c}\text { Jornadas no } \\
\text { trabajadas }\end{array}$ & Huelgas & Participantes & $\begin{array}{c}\text { Jornadas no } \\
\text { trabajadas }\end{array}$ \\
& & & & & & \\
\hline 2006 & 779 & 499.240 & 927.402 & 785 & 1.074 .885 & 5.972 .813 \\
\hline 2007 & 751 & 492.150 & 1.182 .782 & 851 & 1.064 .768 & 7.820 .255 \\
\hline 2008 & 810 & 542.508 & 1.508 .719 & 849 & 1.793 .595 & 8.300 .793 \\
\hline 2009 & 1001 & 653.483 & 1.290 .852 & 888 & 1.434 .223 & 8.932 .991 \\
\hline 2010 & 984 & 340.776 & 671.493 & 958 & 1.401 .662 & 6.674 .058 \\
\hline 2011 & 777 & 221.974 & 485.054 & 961 & 1.059 .256 & 4.133 .785 \\
\hline 2012 & 878 & 323.871 & 1.290 .114 & 1.217 & 1.490 .071 & 8.341 .371 \\
\hline 2013 & 994 & 448.024 & 1.098 .480 & 1.206 & 1.389 .066 & 7.660 .085 \\
\hline 2014 & 777 & 217.047 & 620.568 & 1.335 & 1.457 .731 & 11.057 .320 \\
\hline 2015 & 615 & 170.528 & 497.486 & 1.235 & 1.147 .777 & 4.955 .667 \\
\hline 2016 & 641 & 183.120 & 388.912 & 1.321 & 1.710 .700 & 10.432 .300 \\
\hline
\end{tabular}

Fuentes: Estadística de huelgas y cierres patronales, Ministerio de Empleo y Seguridad Social, España. Encuestas de conflictos con paro, Dirección de Relaciones Laborales, Subdirección de Políticas, Estadísticas y Estudios laborales, Ministerio de Trabajo y Empleo y de la Seguridad Social, Argentina. (*) No se incluyen datos de la huelga de la enseñanza pública y privada del 2013. 
De la lectura de los datos del Cuadro 3 anterior, se desprende, en primer lugar, que el número de huelgas que se produjeron durante el período 2006-2016 en España y Argentina no fue, substancialmente, muy distinto. Sin embargo, sí cabe resaltar de ese comportamiento aparentemente parecido que en España se registró una tendencia evolutiva a la baja desde 2009, con algunos altibajos, mientras que esa tendencia en Argentina se manifestó claramente al alza, prácticamente desde 2006.

En segundo lugar, por lo que se refiere específicamente a España, cabe comentar que el aumento de la conflictividad en términos de huelgas que se experimentó hasta 2009 -con un cierto descenso en 2011, pero con un nuevo ascenso en 2012 y 2013- habría de atribuirse, como ya se explicó en el epígrafe 3, fundamentalmente, al impacto que, entre otras cosas, comportó la crisis económicofinanciera en términos de cierres masivos de empresas ${ }^{6} \mathrm{y}$, del correspondiente despido de millones de trabajadores. Eso no fue obvio, no obstante, para que ( al contrario de lo que postula la teoría económica clásica sobre las huelgas: más huelgas en períodos de auge y menos en períodos de recesión) el número de huelgas creciera ${ }^{7}$

${ }^{6}$ El número de empresas que desaparecieron en España entre 2008 y 2012 es de 53.210 empresas. Datos extraídos del Directorio Central de Empresas del Instituto Nacional de Estadística, España.

${ }^{7}$ En España, los dos principales sindicatos que, ya desde la década de los ochenta, vienen movilizando a los trabajadores para que vayan a la huelga son CCOO y UGT. Estos dos sindicatos cuentan con un respaldo sostenido, desde dicha década, de los trabajadores. La legitimidad de ese respaldo proviene de que, entre ambos, concitan el $80 \%$ de los votos que emanan de las elecciones sindicales que se realizan en las organizaciones y empresas cada cuatro años.
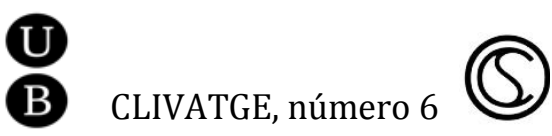
hasta que aparecieron los primeros signos de recuperación económica en 2014. Por tanto, durante el período de crisis más intenso el número de huelgas en España no sólo no descendió, sino que mantuvo un número de huelgas bastante estable.

En tercer lugar, por lo que se refiere al comportamiento de las otras dos variables del Cuadro 3 (participantes en las huelgas y jornadas no trabajadas), es importante remarcar la gran diferencia de las cifras que adquirió la dimensión de ambas: los participantes en las huelgas de Argentina han oscilado entre dos y diez veces más que en España, en particular, conforme nos acercamos al final del citado período, por lo que la capacidad de movilización conseguida por los sindicatos argentinos (CGT, CTA, CTA (autónoma), CGT Azul y Blanca y otros), ha sido, y es, muy importante. Respecto de las jornadas no trabajadas, sucede algo parecido al número de participantes, sólo que las cifras de las diferencias entre ambos países durante ese mismo período eran aún más abultadas: alcanzaron, en algunos años como en 2014 y 2016, un volumen que llegaba a superar en más de 17 y 23 veces el de, respectivamente, España.

Esas extraordinarias cifras alcanzadas en Argentina hay que relacionarlas, sobre todo, con las huelgas generales que se llevaron a cabo en algunos de esos años ${ }^{8}$. El número de huelgas y, en general, la

8 Sólo en 2012, por ejemplo, hubo cuatro convocatorias en ese mismo año que paralizaron buena parte del transporte, los servicios, las actividades docentes, los bancos, la salud y la producción rural. Por su parte, en 2014 hubo dos convocatorias, la segunda de las cuales tuvo un carácter aún más masivo que la de 2012 -al menos en términos de jornadas no trabajadas- y se concentró en el

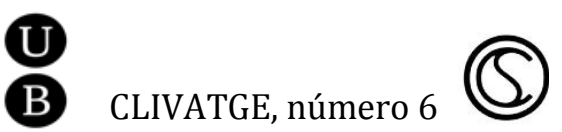


gran movilización que protagonizan los trabajadores de Argentina -no en vano, se corresponde, según la OIT, con uno de los países del mundo occidental que más huelgas lleva a cabo- situaban en 2013 a este país, sólo por debajo de Alemania, en cuanto a número de huelgas. Tras Argentina, no obstante, se ubicaba España, aunque a cierta distancia de este último.

Cabe añadir también que, mientras la orientación de las huelgas en España han estado asociadas a reivindicaciones salariales y de mejora de las condiciones de vida y del propio trabajo, básicamente, de carácter económico-sociales, en cambio, en Argentina las huelgas se han orientado, no sólo a esos objetivos, sino también y, muy particularmente, contra las políticas económicas neoliberales que, en mayor o menor medida, han practicado los diversos gobiernos que ha tenido este país durante los últimos años, y a quienes los sindicatos han hecho máximos responsables de la situación económica que viene padeciendo este país.

\subsection{Análisis de las variables en términos relativos}

sector público, a pesar de que la extensión de esta huelga alcanzó a todos los sectores económicos. En 2016 se volvió a producir una nueva convocatoria que volvió a situar el número de participantes y de jornadas no trabajadas en el segundo puesto del período 2006-2016, afectando, una vez más, al conjunto de la economía, incluido el sector público.

B CLIVATGE, número 6

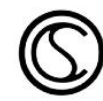


Con el siguiente Cuadro 4 que viene a continuación se pretende ahondar en la comparación de las cifras entre ambos países utilizando para ello nuevas variables para intentar extraer nuevos resultados que puedan complementar y explicar más y mejor las diferencias ya comentadas en el Cuadro 3 anterior.

Para ello, se han creado cuatro nuevas variables o indicadores (Media de participantes por huelga, Media de jornadas no trabajadas por huelga, Media de ocupados por participante y Media de ocupados por jornadas no trabajadas), para ver en qué medida los resultados que se obtuvieron en el Cuadro 3 mantienen o no las diferencias entre Argentina y España alcanzadas en dicho Cuadro.

Evolución de las medias por participante y jornadas no trabajadas en función de las huelgas y ocupados en España y Argentina, 2006-2016 Cuadro 4

ESPAÑA

\begin{tabular}{|c|c|c|c|c|c|c|c|c|}
\multicolumn{9}{|c|}{ ESPANA } \\
\begin{tabular}{|c|c|c|c|c|c|c|}
\hline \\
Año
\end{tabular} & $\begin{array}{c}\text { Medias de } \\
\text { participantes } \\
\text { por huelga }\end{array}$ & $\begin{array}{c}\text { Medias de } \\
\text { jornadas } \\
\text { no } \\
\text { trabajadas } \\
\text { por } \\
\text { huelga }\end{array}$ & $\begin{array}{c}\text { Medias de } \\
\text { ocupados } \\
\text { por } \\
\text { participante }\end{array}$ & $\begin{array}{c}\text { Medias de } \\
\text { ocupados } \\
\text { por } \\
\text { jornadas } \\
\text { no } \\
\text { trabajadas }\end{array}$ & $\begin{array}{c}\text { Medias de } \\
\text { participantes } \\
\text { por huelga }\end{array}$ & $\begin{array}{c}\text { Medias de } \\
\text { jornadas } \\
\text { no } \\
\text { trabajadas } \\
\text { por } \\
\text { huelga }\end{array}$ & $\begin{array}{c}\text { Medias de } \\
\text { ocupados } \\
\text { por } \\
\text { participante }\end{array}$ & $\begin{array}{c}\text { Medias de } \\
\text { ocupados } \\
\text { por } \\
\text { jornadas } \\
\text { no } \\
\text { trabajadas }\end{array}$ \\
\hline 2006 & 640,8 & $1,190,5$ & 40,5 & 21,8 & $1.369,2$ & $7.608,6$ & 13,7 & 2,5 \\
\hline 2007 & 655,3 & $1.574,9$ & 42,1 & 17,5 & $1.251,2$ & $9.189,5$ & 13,9 & 1,9 \\
\hline 2008 & 669,7 & $1.862,6$ & 36,9 & 13,3 & $2.112,6$ & $9.777,1$ & 8,4 & 1,8 \\
\hline 2009 & 652,8 & $1.289,5$ & 26,9 & 14,6 & $1.615,1$ & $10.057,4$ & 10,6 & 1,7 \\
\hline 2010 & 288,7 & 682,4 & 54,8 & 27,8 & $1.151,8$ & $6.995,8$ & 10,8 & 2,3 \\
\hline 2011 & 285,6 & 624,2 & 81,8 & 37,4 & $1,102,2$ & $4.301,5$ & 14,7 & 3,8 \\
\hline 2012 & 368,8 & $1.469,3$ & 53,5 & 13,4 & $1.224,4$ & $6.854,-$ & 10.5 & 1,9 \\
\hline
\end{tabular}

\section{ARGENTINA}

B CLIVATGE, número 6

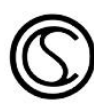




\begin{tabular}{|c|c|c|c|c|c|c|c|c|}
\hline 2013 & 450,7 & $1.105,-$ & 38,2 & 15,6 & $1.151,8$ & $6.351,6$ & 11,6 & 2,1 \\
\hline 2014 & 279,3 & 798,6 & 80,9 & 28,3 & $1.091,9$ & $8.282,6$ & 10,7 & 1,4 \\
\hline 2015 & 277,3 & 808,9 & 108,5 & 36,4 & 929,3 & $4.012,6$ & $\left(^{*}\right)$ & $\left(^{*}\right)$ \\
\hline 2016 & 285,7 & 606,7 & $101,-$ & 47,6 & $1.295,-$ & $7.897,2$ & 8,6 & 1,4 \\
\hline $\begin{array}{l}\text { Promedios } \\
\text { 2006-2016 }\end{array}$ & 441,3 & $1.088,9$ & 65,9 & 24,9 & $1.299,5$ & $7.393,4$ & 11,3 & 2,1 \\
\hline
\end{tabular}

Fuente: Elaboración propia a partir de Estadística de huelgas y cierres patronales, Ministerio de Empleo y Seguridad Social, España; y de Encuestas de conflictos con paro, Dirección de Relaciones Laborales, Subdirección de Políticas, Estadísticas y Estudios laborales, Ministerio de Trabajo y Empleo y de la Seguridad Social; INDEC-EPH, Argentina. (*) Las cifras de ocupados de 2015 no figuran en ninguna de las estadísticas oficiales de Argentina, (**) No se incluyen datos de la huelga de la enseñanza pública y privada del 2013.

De la observación de las cifras contenidas en el Cuadro 4, se pueden deducir las siguientes consecuencias:

a) Por lo que se refiere a España, se puede comprobar que el promedio alcanzado por la suma de las medias de la variable "participantes por huelga" a lo largo del período 2006-2016, se situó en 441,3 participantes por huelga. Ese promedio alcanzó su máximo en $2008(669,7)$ y su mínimo en 2015 (277,3). Estos datos, una vez más, corroborarían la influencia que ha tenido la ya citada crisis económico-financiera en el número de participantes, pues aun habiendo ido, en general, al alza el número de huelgas entre 2008 y 2013 -observadas de forma independiente en el Cuadro 3- la media de participantes por huelga se resintió de forma importante a partir de 2010 y, aunque hubo una cierta recuperación en 2012 y 2013 de los participantes, esas medias volvieron a recaer a los niveles de 2010 
y 2011, durante los últimos años del período evaluado, con un pequeño repunte al alza en 2016.

Por tanto, la tendencia decreciente experimentada ya desde 2009 -aunque con algunos repuntes positivos- $y$, confirmada, sobre todo a partir de 2014, con el descenso del número de huelgas y de participantes, analizados en el Cuadro 3 de forma independiente, se ha podido confirmar ahora con la tendencia de las medias de la variable conjunta "participantes por huelgas", en la medida de que esta última tendencia también ha mostrado un descenso, salvo en los años 2012 y 2013. En resumen, tanto el número de huelgas, especialmente desde 2014, como de participantes en las huelgas, salvo en 2013, han sufrido un descenso en España, tanto si se analiza cada una de esas variables por separado, como si se hace a través de la variable conjunta, con la excepción de 2013.

Por lo que se refiere a Argentina, el citado promedio se situaba en 1299,5 participantes por huelga, con un máximo en 2008 de 2.112,6, coincidiendo temporalmente con España, y un mínimo en 2015 de 929,3, coincidiendo, igualmente, con España. Por su parte, la tendencia de la variable "número de huelgas" y de la "número de participantes" siguieron una tendencia, como ya se vio en el Cuadro 3 , un tanto distinta: mientras las huelgas se incrementaron desde, prácticamente, el inicio hasta el final del período, salvo el leve descenso habido en 2015, los participantes, en cambio, siguieron una trayectoria un tanto sinuosa, pues éstos aumentaron hasta 2008, para volver a descender a cifras, claramente menores, hasta que en 2012 y 2014 volvieron a ascender, para acabar con un repunte importante en

B CLIVATGE, número 6

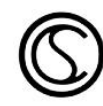


2016. En términos generales, parecería que los aumentos y descensos más o menos continuados a lo largo del período, podrían estar conectados con los años, particularmente más conflictivos como, por ejemplo, huelgas generales, para volver a descender a niveles inferiores de conflictividad y, por tanto, de participantes, en los años posteriores a los más conflictivos.

Por tanto, la variable conjunta "participantes por huelgas", estaría reflejando, al menos en parte, la confluencia de esas dos tendencias (crecimiento de huelgas y estabilización relativa del número de participantes), de cuyo resultado se puede apreciar un cierto declive y estancamiento a partir de 2009. La constatación de la tendencia al declive o al estancamiento de la variable conjunta en Argentina durante los años del período analizado, no es obvio para reconocer que esos participantes constituyen entre dos y tres veces más el número de participantes que consiguió España durante el mismo período. Y eso, sin tener en cuenta que la población ocupada de Argentina es menor que la de España (algo que se verá con más detalles más adelante). En otras palabras, el incremento del número de huelgas que ha sucedido en Argentina durante estos años, no se ha visto correspondido con el mismo crecimiento relativo del número de participantes.

b) Por lo que respecta a la segunda variable conjunta "Medias de jornadas no trabajadas por huelga", los datos del Cuadro 4 muestran que en España el promedio alcanzado por esas medias a lo largo del período 2006-2016, se situó en 1088,9 jornadas no

B CLIVATGE, número 6

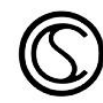


trabajadas por huelga de media, mientras que el valor máximo se registraba en 2008 (1.862,6), y el mínimo en 2016 (606,7). En este marco, se produjo una tendencia de la variable conjunta, primero ascendente hasta 2008 para, a partir de 2009, registrarse un descenso hasta 2012 -año en el que, como ya se ha dicho, se produjo un importante repunte con 1469,3 jornadas no trabajadas por huelga, en buena medida como consecuencia de la huelga general en contra de la Reforma Laboral, el 14 de noviembre - tras lo cual, tuvo lugar un nuevo descenso que se ha mantenido hasta 2016.

Esta tendencia coincide, en buena medida, con la que ya se ha analizado en el Cuadro 3, cuando se procedió a observar el comportamiento seguido por las variables "número de huelgas" y "jornadas no trabajadas" de forma independiente. Por ello, se puede afirmar que, lógicamente, si ambas variables tuvieron un comportamiento a la baja, la trayectoria de la variable conjunta "jornadas no trabajadas por huelga" habría de sufrir la misma tendencia al descenso en España, a pesar de los repuntes habidos en 2008 y 2012.

Respecto a Argentina, el promedio alcanzado por la variable conjunta "Medias de jornadas no trabajadas por huelgas" a lo largo del período 2006-2016, se situó en 7.393,4 jornadas no trabajadas, mientras que el valor máximo se registraba en $2009(10.057,4)$, y el mínimo en $2015(4.012,6)$. La evolución seguida de tales medias ha sido un tanto parecida a la de España -sólo que con cifras de jornadas no trabajadas por huelgas mucho más abultadas- en la medida que hubo un ascenso hasta 2009 pero, a partir de 2010 se produjo un

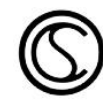


descenso, con algunos repuntes al alza destacables en 2012, 2014 y 2016, coincidiendo con las tres huelgas generales habidas en estos años. En todo caso, las cifras que se alcanzaron a partir de 2010 nunca superaron, salvo en 2016, las que se habían alcanzado en 2009 o, incluso, antes en 2007 y 2008, salvo en 2016.

Por tanto, el ascenso tendencialmente creciente de forma independiente de la variable "número de huelgas" junto a una tendencia de la variable "jornadas no trabajadas", igualmente propensa al crecimiento, especialmente, a partir de 2012, conllevaría, una vez más, a matizar la tendencia, relativamente, descendente de la variable conjunta "Medias de jornadas no trabajadas por huelgas", a partir de 2010, en el sentido de que los valores adquiridos por ésta en el Cuadro 4, no serían más que el refleja de una combinación de la tendencia al crecimiento del número de huelga y de la trayectoria irregular (ascensos y descensos continuados) experimentada por la variable "jornadas no trabajadas" por su cuenta durante el citado período.

En definitiva, y de forma parecida a lo que ha sucedido con los participantes, el incremento del número de huelgas que ha existido en Argentina durante el período 2006-2016, no se ha visto correspondido con la misma regularidad ascendente que ha seguido el número de jornadas no trabajadas. Eso no obvia que, de nuevo, las jornadas no trabajadas en Argentina eran entre seis y dieciocho veces mayores en términos absolutos que las que se alcanzaron en España durante el mismo período 2006-2016. Y eso, como también se ha dicho antes, sin tener en cuenta que la población ocupada de

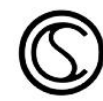


Argentina es menor que la de España (algo que se verá con más detalle a continuación)

c) Respecto a la relación de estas dos mismas variables ("participantes" y "jornadas no trabajadas") con las nuevas variables "ocupados por participantes" y "ocupados por jornadas no trabajadas", es necesario, antes de comparar las medias obtenidas de esas dos nuevas variables, ofrecer los datos de los ocupados que se han registrado en ambos países a lo largo del período 2006-2016, a fin de saber si la dimensión ocupacional es una variable que modifica las tendencias que se han obtenido con las huelgas como referente comparativo. También hay que aclarar que los resultados así obtenidos no podrán ser comparados con los que se alcanzaron con las huelgas como referente, pues la sustitución de las huelgas por ocupados como nuevo referente, da lugar a cifras de compleja comparación (carecen de homogeneidad), con las obtenidas con las huelgas como referente. En el Cuadro 5 que viene a continuación se exponen las cifras que ha alcanzado la población ocupada de Argentina y de España.

Evolución de la población ocupada de España y Argentina, 2006-2016 (en miles de ocupados). Cuadro 5

\begin{tabular}{|c|c|c|c|c|c|c|c|c|c|c|c|}
\hline Años & $\mathbf{2 0 0 6}$ & $\mathbf{2 0 0 7}$ & $\mathbf{2 0 0 8}$ & $\mathbf{2 0 0 9}$ & $\mathbf{2 0 1 0}$ & $\mathbf{2 0 1 1}$ & $\mathbf{2 0 1 2}$ & $\mathbf{2 0 1 3}$ & $\mathbf{2 0 1 4}$ & $\mathbf{2 0 1 5}$ & $\mathbf{2 0 1 6}$ \\
\hline España & 20.195 & 20.717 & 20.055 & 18.890 & 18.674 & 18.153 & 17.339 & 17.135 & 17.569 & 18.094 & 18.508 \\
\hline Argentina & 14.750 & 14.795 & 15.181 & 15.192 & 15.175 & 15.575 & 15.761 & 16.083 & 15.771 & --- & 14.712 \\
\hline
\end{tabular}

B CLIVATGE, número 6

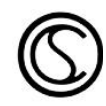


Fuente: Encuesta de Población Activa (EPA), Ministerio de Empleo y Seguridad Social, España. Ministerio de Trabajo y Empleo y de la Seguridad Social, INDEC, Argentina.

Una vez conocida la dimensión ocupacional de ambos países, cabe recordar también que, si las medias de los participantes y de las jornadas no trabajadas de los apartados a) y b) estaban condicionadas por la trayectoria que había seguido el número de huelgas de España y Argentina, es decir, por el grado de conflictividad sociolaboral expresado en términos de más o menos huelgas registradas en cada año en esos dos países; ahora las medias de los participantes y de las jornadas no trabajadas estarán condicionadas por la trayectoria que haya mantenido el número de ocupados, es decir, por la evolución que haya seguido la creación o destrucción de ocupación (por cuenta propia y por cuenta ajena), en estos dos países ${ }^{9}$.

Pues bien, por lo que se refiere a España, se puede comprobar que el promedio alcanzado por la variable "medias de ocupados por

9 Debe de tenerse en cuenta que la introducción de la variable "ocupados" como nueva variable referente de las comparaciones, al ser "externa" a las que son propias de las huelgas, aunque no permite comparar los resultados con los obtenidos con las huelgas de referente, sí que facilita que se puedan hacer comparaciones del tipo: "cuántos ocupados se necesitan para que un participante participe en una huelga" y, de igual modo, con las jornadas no trabajadas. En cambio, no tiene demasiado sentido realizar este tipo de comparaciones con las huelgas como referente. Por ejemplo, "cuántas huelgas son necesarias para que un participante participe en una huelga".

B CLIVATGE, número 6

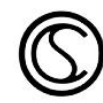


participante" 10 a lo largo del período 2006-2016, se situó en 65,9 ocupados por participante, con un máximo de 108,5 en 2015 y un mínimo de 26,9 en 2009. En este marco, se produjo una tendencia de estas medias bastante irregular: primero, descendiente desde 2007 a 2009, para ascender hasta 2011 y volver a descender hasta 2013, a partir de lo cual se volvió a ascender hasta 2015 y, finalmente, retroceder, con un leve repunte al alza en 2016.

Esta elevada variabilidad ${ }^{11}-4$ veces de diferencia entre el valor mínimo de 26,9 y el máximo de 108,5- de la trayectoria de la variable conjunta "ocupados por participantes", no sólo debería de atribuirse al resultado, también variable, de combinar la trayectoria que siguió, de forma independiente, la variable "Participantes" (ver Cuadro 3), y la que, igualmente registró, en este caso, la variable "ocupados" por su cuenta -un mínimo de 17.135.200 millones de ocupados en 2013 y un máximo de 20.717 .900 en 2007, (ver Cuadro 5); sino que indicaría un elevado grado de variabilidad del número de participantes con relación a la que ha sufrido el número de ocupados a lo largo de dicho período en España.

\footnotetext{
${ }^{10}$ Para el cálculo de las medias con los ocupados de referente, se ha situado a los ocupados en el numerador y no en el denominador (como con las huelgas), para que los resultados de esos cálculos no puedan ser decimales. En todo caso, los resultados así obtenidos no modifican los resultados del análisis de la comparativa que se va a hacer de los datos de España y Argentina.

${ }^{11}$ Se entenderá aquí por variabilidad o grado de dispersión de las variables analizadas, como la diferencia entre el valor máximo y el mínimo que una determinada variable alcanza a lo largo de una serie de valores entre, en este caso, 2006 y 2016. Este cálculo sólo se llevará a cabo cuando la ocupación sea el referente comparativo.
}

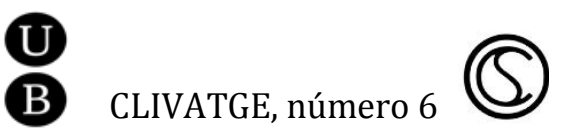


Esto mostraría que las medias de ocupados por participante han seguido un itinerario bastante cambiante (ver Cuadro 4), o lo que es lo mismo, que los aumentos o descensos habidos en el número de ocupados de cada año a lo largo del período analizado no se han visto "compensados" por los aumentos o descensos que se han producido en los participantes o viceversa. Si las cifras de los ascensos o descensos de participantes y ocupados hubieran crecido o descendido en el mismo porcentaje, las proporciones que reflejarían las medias de cada año no se hubieran modificado.

Dicho lo anterior $\mathrm{y}$, por lo que se refiere a Argentina, la trayectoria seguida por la variable conjunta "medias de ocupados por participante" ha sido, no sólo bastante menos irregular que la seguida en España, sino que, a diferencia de este último país, la tendencia de esa variable, igualmente con vaivenes, ha ido al descenso. Ya desde 2006, los ocupados por participante descendieron hasta 2008, para aumentar hasta 2011 (año en el que se alcanzó el máximo (14,7 ocupados por participante), para volver a descender en $2016(8,6)$ a unos niveles mínimos parecidos a los que se alcanzaron en 2008 (8,4 ocupados por participante), durante dicho período.

También a diferencia de España, estas cifras, no sólo adquirieron unas dimensiones menores - es decir, que la cifra de ocupados para que participara un participante en las huelgas de Argentina tendió, en general, a ser cada vez menor -al contrario de lo sucedido en España- sino que las disparidades entre los valores máximos y los mínimos también han sido menores: mientras la disparidad o variabilidad de las medias de ocupados por participante alcanzó 4

B CLIVATGE, número 6

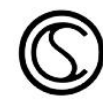


veces de más entre el valor máximo y mínimo en España, como ya se vio anteriormente, en cambio, esa disparidad fue sólo de 0,75 veces en Argentina, lo cual indicaría que las medias de ocupados por participante se han mantenido bastante más homogéneas o estables en Argentina que en España. 0 lo que es lo mismo, que los aumentos o descensos habidos en el número de ocupados en Argentina a lo largo del período analizado (con una disparidad o diferencia relativa entre 16.083.000 ocupados de máximo en 2013 y 14.712 .000 ocupados de mínimo en 2016, tal como ya se vio en el Cuadro 5), se han visto bastante "compensados" por los aumentos o descensos que se han producido en los participantes, en comparación con lo que ha sucedido en España.

d) Finalmente, el promedio alcanzado por la variable "Medias de ocupados por jornadas no trabajadas" en España, a lo largo del período 2006-2016, se situó en 24,9 ocupados por jornada no trabajada, con un máximo de 47,6 en 2016 y un mínimo de 13,3 en 2008. En este marco, se produjo, una vez más, una tendencia irregular de la trayectoria seguida por esa variable. En primer lugar, un descenso entre 2006 y 2009, para ascender hasta 2011 y volver a descender en 2012, para acabar ascendiendo de nuevo hasta 2016.

Esta elevada variabilidad de la trayectoria de la variable conjunta "ocupados por jornadas no trabajadas" en España (3,6 veces de diferencia entre el valor mínimo -13,3- y el máximo -47,6-) ponía de manifiesto, de nuevo, el elevado grado de disparidad entre el
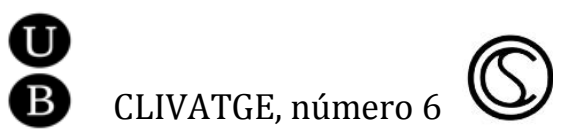
número de jornadas no trabajadas y el número de ocupados habidos en España a lo largo del período 2006 y 2016.

Además, la tendencia seguida por la variable conjunta "Medias de ocupados por jornadas no trabajadas" ha sido, prácticamente, contraria a la que, de forma independiente, siguió la variable "jornadas no trabajadas" por su cuenta pues, entre 2006 y 2008, esta última, no sólo no descendió como sucedió con las medias, sino que aumentó. Sin embargo, a partir de 2009 inició un descenso que, prácticamente, sería constante, sólo modificado en 2012 fruto de, como ya se ha insistido, la huelga general que hubo ese mismo año. Todo lo contrario de lo que, en general, sucedió con la variable conjunta pues descendió hasta 2008 y ascendió, casi continuadamente hasta 2016 salvo la caída de 2012.

Por tanto, es lógico pensar que, si la tendencia de la variable conjunta ha sido opuesta a la que ha seguido la variable "jornadas no trabajadas" por su cuenta, eso se debe más a los cambios habidos en el comportamiento de la ocupación que a las variaciones registradas en las jornadas no trabajadas por su cuenta, puesto que cuando bajaba el número de jornadas no trabajadas aumentaban las medias por ocupado por jornadas no trabajadas. En definitiva, la tendencia de estas medias en España ha demostrado que, desde 2012, cada vez ha sido necesario un mayor número de ocupados para que se produjera una jornada no trabajada.

Con relación a Argentina, el promedio que alcanzó la variable "Medias de ocupados por jornadas no trabajadas", a lo largo del período 2006-2016, se situó en 2,1 ocupados por jornada no

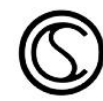


trabajada, con un máximo de 3,8 en 2011 y un mínimo de 1,4 en 2016. En este marco, se produjo una tendencia, un tanto irregular, de la trayectoria de esa variable, la cual experimentó, en primer lugar, un descenso desde 2006 hasta 2009, para remontar hasta 2011 y descender de nuevo en 2012, para volver a elevarse en 2013 y acabar descendiendo hasta 2016. Con los anteriores datos, es fácil deducir que, para que hubiera una jornada no trabajada en las huelgas de Argentina durante el período analizado, se requerían muchos menos ocupados que en España (24,9 ocupados de media en España por 2,1 en Argentina: más de once veces entre ambas cifras).

De los datos anteriores se derivó también que la variabilidad de la variable conjunta "ocupados por jornadas no trabajadas" alcanzó en Argentina 2,7 veces la diferencia relativa entre el valor mínimo -1,4y el máximo -3,8-, lo cual, de nuevo, no sólo debería de atribuirse al resultado, igualmente variable que siguió, de forma independiente la variable "Jornadas no trabajadas" (ver Cuadro 3), sino también a la que registró la variable "ocupados" por su cuenta (la diferencia relativa ente 14.712.000 ocupados de mínimo en 2016 y de 16.083.000 de máximo en 2013, tal como ya se vio en el Cuadro 5), lo cual ponía de manifiesto el menor grado de dispersión de las medias de la variable conjunta (2,7 veces), con relación al que existió en España (3,6 veces), o lo que es lo mismo, que los, relativamente, pequeños aumentos o descensos que ha habido en el número de ocupados en Argentina a lo largo del período analizado se han visto bastante más compensados por los aumentos o descensos que se han

B CLIVATGE, número 6

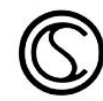


producido en el número de jornadas no trabajadas, en comparación con lo que ha sucedido en España.

\section{Conclusiones}

Para iniciar estas conclusiones es inevitable empezar haciendo referencia a las fuentes oficiales de donde se han obtenido los datos que aquí se han utilizado. En términos generales, hay una tendencia de los servicios estadísticos oficiales a infra-registrar, al menos en una parte, los conflictos sociales que realmente suceden. Y es que suelen haber más conflictos y huelgas que los que se quieren dar a conocer oficialmente (Joyce, 2015: 3). Bien porque la autoridad laboral competente desconoce su existencia, pero también porque hay huelgas que no proceden de conflictos sociolaborales.

Probablemente, los datos que aquí se han utilizado, tanto de España, como de Argentina, puedan padecer de esa tendencia, por mucho que sean los que aparecen en las diversas fuentes utilizadas. En el caso de España, a esa tendencia general a intentar disminuir el registro del número de huelgas, hay que añadir, como ya se vio en el epígrafe 3, la existencia del servicio oficial de mediación, cuyo principal cometido consiste en evitar la convocatoria de éstas. Con todo ello, se consigue que, de no existir tal mediación, el número de huelgas registradas podría haber sido superior.

Por lo que se refiere a Argentina, la tendencia al infra-registro podría proceder, básicamente, de las dificultades que muestran algunos de los servicios oficiales de estadística para contabilizar

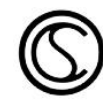


algunos de los datos relacionados con el mercado de trabajo (por ejemplo, los datos de los ocupados de 2015), a lo que se sumaría la no coincidencia de algunos de los datos sobre huelgas según era la fuente a las que se recurría.

Sobre la validación o no de las premisas teóricas que se expusieron en el apartado teórico, cabe decir que, en España, la perspectiva teórica que defiende que, si existe un ciclo económico expansivo y una posición robusta en el mercado de trabajo, los trabajadores tendrán una mayor fuerza negociadora para, si es necesario, hacer huelga; tal teoría podría validarse sólo en parte (antes de 2009), porque una vez llegada la crisis económica-financiera a partir de ese año, ha sido cuando más huelgas se produjeron y, tras la recuperación económica en 2014, no sólo no crecieron esas huelgas, sino que tendieron a la baja.

Así pues, los hechos contradicen esta teoría por lo que al menos en su conjunto no se podría validar. Ni la teoría político-institucional ni la de la confianza (al menos en su totalidad) explicarían tampoco, por su parte, la trayectoria que han seguido las huelgas en España, teniendo en cuenta que el Estado, desde hace décadas, interviene muy poco en el ámbito de las relaciones laborales (dejando como agentes sociales en la negociación colectiva a la patronal y a los sindicatos en solitario, pero sabiendo que dicha patronal es hegemónica en ese ámbito desde principios de los ochenta), y por tanto juega un papel residual en ese espacio. En ese sentido, los grandes sindicatos (CCOO y UGT), sólo consiguen la confianza de los trabajadores para hacer huelga en algunas actividades industriales y algunos servicios

B ClivatGe, número 6

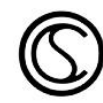


públicos pero están bastante ausentes del resto de actividades económicas y, sólo obtienen su legitimidad a través de las elecciones sindicales (ambos obtienen el 80\% de los votos desde hace más de 30 años), en las que aún participan una gran mayoría de los asalariados.

Por lo que se refiere a Argentina, si bien las motivaciones de la mayoría de las huelgas no han sido ajenas a los ciclos económicos y a la posición más o menos robusta de los trabajadores en el mercado de trabajo, las huelgas han estado relacionadas también con otros aspectos tan o más importantes como la mayor presencia del Estado en las relaciones laborales y el gran poder de convocatoria que tienen los sindicatos (al menos en comparación con España), por lo que es fácil deducir la existencia de un panorama sociolaboral más próximo a los postulados de las teorías político-institucional y la de la "confianza".

Ambas teorías explicarían también el por qué la mayor parte de las huelgas en este país se llevan a cabo en el sector público y contra el Estado y en mucha menor proporción en el sector privado. Respecto a la primera teoría, entraría en juego el rol del Estado como agente más o menos creador de ocupación pública $\mathrm{y}$, por tanto, su contribución a que exista un menor grado de paro, pero también como máximo responsable del tipo de políticas económicas y de empleo que se aplican en la economía y sus repercusiones sobre la población ocupada.

Respecto a la teoría de la confianza, habría que hablar de las causas de las grandes cifras de la movilización obrera de los últimos decenios en Argentina. Estas cifras no sólo son la expresión del

B CLIVATGE, número 6

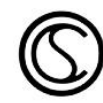


malestar de una gran parte de la población sobre sus condiciones de vida y de trabajo, sino que también son el reflejo de la gran confianza que existe entre los trabajadores sobre la eficacia que consiguen los sindicatos en cuanto a la gran participación que se produce en las huelgas, en particular, en las generales. De no haber esa confianza, el volumen de las movilizaciones sería mucho menor, por mucho que existan divisiones en el movimiento sindical y discrepancias ideológicas a la hora de convocar las movilizaciones y las huelgas.

El objetivo de este análisis era comparar la evolución de las huelgas, en los dos países considerados, para tratar de deducir sus condiciones, en términos de participación y jornadas no trabajadas, a fin de conocer en qué medida los resultados, en términos de acciones de protesta, estaban más o menos mediados por el papel que han jugado los sindicatos y el propio Estado.

Pues bien, los resultados han permitido constatar, en primer lugar, que las huelgas en España siguieron una trayectoria relativamente ascendente desde 2002, con un punto máximo en 2009, a partir del cual se inició un paulatino descenso, aunque con unas cifras aún elevadas, para llegar a 2014, año en el que empezó el declive que aún hoy pervive. De la trayectoria que siguieron las huelgas en España se pudo comprobar, al menos, dos aspectos: a) no respondían a la teoría económica de las huelgas, como ya se ha visto, dado que crecían en períodos de crisis económica y no al contrario, y b) la institucionalización de los sindicatos y de los mecanismos de mediación han limitado el número potencial de conflictos sociales y de huelgas, respectivamente.

B CLIVATGE, número 6

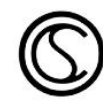


En segundo lugar, este trabajo procedió a comparar los datos absolutos de huelgas, participantes y jornadas no trabajadas de España con los que se disponían de Argentina. El resultado fue que, a pesar de que el número de huelgas entre ambos países no fue substancialmente distinto, sí lo fue la evolución de las tendencias de ambos países: mientras en España esa tendencia inició una trayectoria clara a la baja en 2010, con algunos repuntes al alza, en cambio en Argentina se manifestó claramente al alza, prácticamente desde 2006. Por lo que se refiere a los participantes, el incremento habido en España hasta 2009, inició un descenso prácticamente imparable hasta final del período analizado, coincidiendo en el tiempo con el itinerario seguido por las huelgas y, en buena medida, por las jornadas no trabajadas. Por el contrario, el ascenso de las huelgas en Argentina se correspondió, en términos generales y con algunos altibajos, con el recorrido que siguieron los participantes y, en general, con las jornadas no trabajadas.

En tercer y último lugar, el análisis en términos relativos con la introducción de variables conjuntas con referentes en las huelgas y en los ocupados de cada país, sirvió para ponderar y, en algunos casos, modificar los resultados obtenidos con los datos absolutos. Las medias de huelgas por participantes y por jornadas no trabajadas permitieron, en general, atenuar parte de las divergencias que se suelen producir cuando se trabaja con datos absolutos. En España, las medias de participantes con el referente de huelga mostraron que, desde 2010, la tendencia ha ido, con algún altibajo, a la baja, mientras que las medias de jornadas no trabajadas siguieron un itinerario

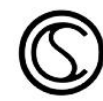


parecido, sólo modificado por la huelga general que hubo en 2012, que representó un repunte importante de la media de esas jornadas por huelga. Respecto a las medias con el referente de "ocupados", la tendencia fue la de necesitar cada vez más ocupados pera que un participante participara en una huelga, mientras que esa fue también la tendencia de las jornadas no trabajadas, con algunos altibajos, llegándose a un mínimo de ocupados necesarios para realizar una jornada no trabajada también en 2012.

Respecto a esas mismas medias en Argentina, se comprobó que el número de participantes con el referente de huelga también tuvo un comportamiento a la baja desde 2009 , mientas que las jornadas no trabajadas con ese mismo referente tendieron también, con algunos repuntes al alza en 2014 y 2016, a la baja desde 2010. Finalmente, las medias por participante con el referente de ocupado se manifestaron claramente a la baja, ya en 2008, pero, sobre todo, a partir de 2012, mientras que esas mismas medias por jornadas no trabajadas con ese mismo referente, siguieron un recorrido un tanto más irregular, pero con una clara tendencia al descenso a partir de 2012 que, junto a 2014 y 2016, marcarían los mínimos de ocupados que se necesitaban para que una jornada no se trabajara en las huelgas de esos años en Argentina.

En otras palabras, mientras las diferencias entre España y Argentina de las medias por participante con el referente de ocupado fueron entre cuatro y ocho veces más elevadas en Argentina, en cambio, esas diferencias entre estos dos mismos países con ese mismo referente, las medias por jornada no trabajada supusieron unas

B CLIVATGE, número 6

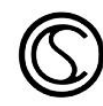


diferencias de entre ocho y treinta veces superiores respecto a España.

En ese sentido, cabría añadir que el análisis en términos relativos con la introducción de las variables conjuntas ha servido para comprobar que cuando se comparaban en términos relativos los participantes y las jornadas no trabajadas con los ocupados como referente, las diferencias entre España y Argentina se acentuaban, más que cuando se utilizan las huelgas como referente de comparación pues, aun habiendo algunas diferencias en el número de huelgas entre estos dos países, las diferencias no son numéricamente tan significativas como las que existen con el número de ocupados.

Sin duda, la mayor combatividad de los trabajadores argentinos sigue siendo una causa que explicaría las grandes diferencias de las dimensiones que toman los principales componentes de las huelgas aquí estudiados (participantes y jornadas no trabajadas), pero el menor tamaño ocupacional de Argentina respecto de España (entre un 20\% y un 25\% en función del mercado de trabajo de cada año) parece destacar aún más las diferencias en el comportamiento del conflicto laboral de uno y otro país. Es decir, con menos ocupados de media que en España, en Argentina se han logrado mayores cifras de participantes y de jornadas no trabajadas como actos de la protesta laboral.

Por último, ahora sólo cabe realizar unos últimos comentarios, de carácter político:
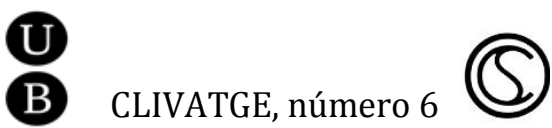
Más allá del importante número de huelgas que se producen en Argentina, parecería que, en la base de esa gran conflictividad, existe una tradición histórica de tipo "peronista", asociada a una ideología de tipo "populista-izquierdista", bien arraigada desde hace muchas décadas y enraizada en una parte importante de la sociedad argentina y que sustenta ideas y valores propicios a la rebelión ante situaciones percibidas como injustas y que se canaliza, básicamente, a través de los sindicatos. Por otro lado, la histórica mayor confianza en el papel social del Estado en Argentina explicaría, al menos en parte, el gran volumen de huelgas que se vienen realizando contra el sector público, al entender los trabajadores que ese Estado $-\mathrm{y}$ no tanto los empresarios, aunque también estos- es el máximo responsable de las políticas económicas que han practicado los diversos gobiernos que han conducido a las sucesivas crisis económicas y a las grandes desigualdades y pobreza de una parte muy importante de la población de este país. El Estado, de ese modo, en tanto que incapaz o sin voluntad real de intervenir en profundidad en las desigualdades que provoca el mercado libre de los bienes y servicios y de las propias personas en el mercado de trabajo, no ha sabido o no ha podido revertir el curso de tales desigualdades y, por ello, se ha acabado convirtiendo en el blanco, directo o indirecto, de muchas de los conflictos y huelgas que se producen en Argentina. Por tanto, no sólo hay en Argentina más motivos objetivos para que surja la conflictividad social y la necesidad de hacer huelga (mayor desigualdad social, porcentajes más elevados de pobreza y marginalidad, etc., que en España), sino que la percepción subjetiva de

B CLIVATGE, número 6

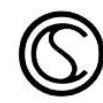


injusticia (conciencia de clase) es más elevada que en España. En este sentido, en España el sentimiento de injusticia percibido por las desigualdades de riqueza que se producen en el mundo del trabajo y a consecuencia del mercado económico - a través de la desigual distribución de la renta y del patrimonio- también existe, pero tiende a canalizarse, en parte, a través del poco Estado de bienestar que aún queda, tras su cuasi desaparición por parte del neoliberalismo aún en vigor. Cuando ese "colchón" no es suficiente para hacer frente al crecimiento del paro y de la pobreza, la movilización de los trabajadores reactiva la conflictividad contra el Estado y los empresarios, pero como ya se ha visto en los epígrafes anteriores, sin la fuerza que poseen los trabajadores de Argentina. El menor nivel de conciencia de clase de los trabajadores españoles, al menos en comparación con los de Argentina, se ha traducido, desde hace décadas, en un descenso paulatino del número de huelgas, del número de participantes y de la prolongación de las jornadas no trabajadas en esas huelgas, sin que los principales sindicatos y de partidos políticos como el socialista, hayan asumido su responsabilidad al respecto.

\section{Bibliografía}

Alonso, L. E. (1991), Conflicto laboral y cambio social. Una aproximación al caso español, en Miguélez, F. y Prieto, C., Las relaciones laborales en España, Madrid, Siglo XXI, pp. 403-426.

B CLIVATGE, número 6

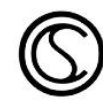


Ashenfelter, Orley, and Johnson, George E. (1969), Barganaing Theory, Trade Unions and Industrial Strike Activivity, American Economic Review, 59, pp. 35-49

Brown, Henry P. (1990), The Changing Contours of British IndustrialRelations. A Survey of Manufacturing Industry, London: Blackwell

Callinicos, Alex (2014), Thunder on the Left, International Socialism, 143, summer, London

Cameron, D. R. (1991), Democracia social, corporatismo, inactividad laboral y representación de intereses económicos en la sociedad capitalista avanzada, en

Cliff, Tony (1978), Where do we Go from Here?, Socialist Review, 1, april

Davidson, Neil (2013), The Neoliberal Era in Britain: Historical Developments and Current Perspectives, International Socialism, 139, summer, London. www.isj.org.uk/id=908

Duarte, Marisa Elizabeth (2007), Las huelgas generales en España de 1982 a 2002: entre la reforma laboral, el conflicto social y la política competitiva, Barcelona: Universidad de Barcelona (tesis doctoral).

Estadísticas de huelgas y de cierres patronales (2017), Ministerios de Empleo y Seguridad Social, Madrid

García Calavia, M. A. (2008), Las huelgas laborales en el Estado español, ARXIUS, 18, pp. 11-33

Goldthorpe, John, (Comp.), Orden y conflicto en el capitalismo contemporáneo, Madrid: Ministerios de Trabajo y Seguridad Social, pp.207-251

Grupo de investigación de relaciones laborales (2016), Grado de relaciones laborales, Universidad de Barcelona

Hyman, Ricard (1984), Relaciones industriales. Una introducción marxista. Madrid: Blume. 
Jiménez-Martín et al (1996), Algunos factores explicativos de la existencia de huelgas durante la negociación colectiva en España, Investigación Económica, XX, 2, pp. 217-241

Joice, Simon (2015), Gran Bretaña, por qué hay tan pocas huelgas, Sin Permiso, enero

Juan Albalate, Joaquín (2015), Trabajo, mercado de trabajo y relaciones laborales, Madrid: Técnos

Kelly, John (1998), Rethinking Industrial Relations: Mobilisation, Collectivism and Long Waves, London: Routledge.

Korpi, W. y Shalev, M. (1979), Strikes, Industrial Relations and class conflicte in Capitalist Societies, British Journal of Sociology, 30-2, 167-187

Luque, D. et al (2008), Un análisis regional de la actividad huelguística en España, Revista Española de Investigaciones Sociológicas, $\mathrm{n}$ 124, pp. 107-140

Marco, M. L. y Tamborero, P. (2001), Las formas de finalización de las huelgas: análisis de la intervención de terceros en España, 1986-1999, Revista del Ministerio de Trabajo y Asuntos Sociales, 31, pp. 115-131

Memoria Sociolaboral, Consejo Economico y Social, resultados 2016, Ministerio de Empleo y Seguridad Social, Madrid

Ministerio de Trabajo, Empleo y Seguridad Social, Argentina,

http://www.trabajo.gov.ar/

Organización Internacional del Trabajo (1996-2012), Estadísticas internacionales de huelgas, Ginebra. http://laborsta.ilo.org/what_s_new_E.html

Tilly, C. y Shorton, E. (1971), The Shape of Strikes in France 1830-1968, Comparative Studies in Society and History, 13-1, pp. 60-86 